\title{
Modyfikacja natryskiwanych powłok aluminiowych na stali skoncentrowanym źródłem ciepła
}

\section{Modification of sprayed aluminum layers on steel substrate by the concentrated heat source}

\section{Streszczenie}

W pracy przedstawiono wstępne wyniki badań nad wytwarzaniem powierzchniowych powłok ochronnych Fe-Al na podłożu stalowym. Powłokę opartą na fazach międzymetalicznych z układu Fe-Al otrzymano w dwustopniowym procesie natryskiwania czystego aluminium na podłoże stalowe oraz przetapiania otrzymanej warstwy Al z żelazem z podłoża. Zapoczątkowana przy przetapianiu synteza aluminium z żelazem umożliwiła otrzymanie powłoki składającej się ze stopu na bazie uporządkowanej fazy międzymetalicznej, co potwierdzone zostało badaniami twardości oraz dyfrakcji rentgenowskiej. Opracowana metoda wytwarzania powłoki Fe-Al jest znacznie tańsza od innych metod nanoszenia powłok, wykorzystujących komercyjnie przygotowany materiał powłokowy Fe-Al. Ponadto, proces przetapiania znacząco zwiększa przyczepność powłoki do podłoża (w stosunku do powłok natryskiwanych), zbliżając ją do wartości osiąganych w procesach napawania.

\section{Abstract}

The paper presents the initial results of research on producing surface protective coatings made of Fe-Al intermetallic compounds on the steel substrates. The Fe-Al coating is obtained in two-step process. First, the steel substrate is thermally sprayed with pure aluminum having thickness about 0,2 $\mathrm{mm}$. This way both components (Fe, $\mathrm{Al}$ ) are prepared for subsequent melting and synthesis. In the final step, the aluminum coating is remelted together with the steel substrate by the microplasma beam. The formation of Fe-Al intermetallic compound has been verified by the microhardness and X-ray diffraction measurements of analyzed coatings. The developed method is the cheap alternative comparing to other surface modification processes utilizing commercially prepared intermetallic coating materials. Beside that, the remelting process substantially increases the coating bond strength reaching levels observed for hardfacing processes.

\section{Wstęp}

Od około 20 lat fazy międzymetaliczne są postrzegane jako materiały funkcjonalne o specyficznych właściwościach chemicznych i fizycznych. Na skutek intensywnych badań naukowych zagadnień dotyczących faz międzymetalicznych i lepszego poznania tej grupy

Mgr inż. Grzegorz Gontarz, dr inż. Tomasz Chmielewski, dr hab. inż. Dariusz Golański - Politechnika Warszawska. materiałów są one coraz szerzej stosowane [1, 2]. Utrudnienia $w$ ich stosowaniu wynikają $z$ wysokiej kruchości $w$ temperaturze otoczenia, lecz również $z$ trudności wytwarzania z nich elementów o użytkowych wymiarach charakteryzujących się litą budową o drobnoziarnistej mikrostrukturze, pozbawionej mikropęknięć i innych nieciągłości. Obecnie duże zainteresowanie towarzyszy materiałom na bazie związków międzymetalicznych z układu Fe-Al. Jest to efektem m.in. względnie niskiej ceny $w$ stosunku do innych grup materiałów aparatach na fazach międzymetalicznych. Istotne składniki kosztów to koszt materiałów podstawowych oraz koszt technologicznego procesu wytwarzania. 
Obecnie stopy na bazie faz międzymetalicznych wytwarzane są przez topienie i odlewanie, które postrzegane są jako tradycyjne metody, niezupełnie wystarczające. Nowoczesne techniki wytwarzania oparte są głównie na metalurgii proszków - tradycyjnych technikach konsolidacji proszków składników podstawowych lub również ich złożonych wieloetapowych odmianach [3]. W znakomitej większości aplikacji faz międzymetalicznych w przemyśle służą one do wytwarzania różnego rodzaju powłok powierzchniowych o charakterze ochronnym. Jednak ich nakładanie jest kosztowne. Najczęściej materiał powłokowy to proszek wcześniej przygotowanych i rozdrobnionych faz międzymetalicznych. Natryskiwanie termiczne faz międzymetalicznych jest od wielu lat stosowane w przemyśle i ciągle rozwijane. Oprócz wielu niekwestionowanych zalet warstw natryskiwanych trzeba również zwrócić uwagę na ich słabe strony wynikające głównie z ograniczeń technologii i metody wytwarzania. Należą do nich skłonność do rozwarstwiania, ograniczona przyczepność warstwy do podłoża < $40 \mathrm{MPa}$ (w teście na rozrywanie) [4], kilkuprocentowa porowatość, maksymalna grubość ograniczono do ok. 0,4 mm oraz ograniczona odporność na skupione naciski [4].

Autorzy zaproponowali dwuetapowy proces technologiczny nawiązujący w części do tradycyjnych metod spajania. W pierwszym etapie na podłoże natryskiwana jest łukowo warstwa czystego aluminium, a w drugim etapie jest ona przetapiana skoncentrowaną wiązką ciepła (mikoplazmy). W obszarze powłoki i podłoża następuje synteza aluminium z żelazem prowadząca do powstania w warstwie fazy międzymetalicznej Fe-Al. Podobne badania z wykorzystaniem skoncentrowanej wiązki lasera do przetapiania aluminium umożliwiły wytworzenie twardej fazy Fe-Al w powłoce [5]. W tym przypadku zastosowanie wiązki mikroplazmowej zdecydowanie uprościłoby proces przetapiania i znacząco obniżyło jego koszt. Zastosowany sposób wytwarzania stopu na bazie uporządkowanej fazy międzymetalicznej z zakresu Fe-Al jest zupełnie nowym rozwiązaniem. Powłoka bazująca na fazie międzymetalicznej z układu Fe-Al jest wytwarzana in-situ.

\section{Wyniki badań}

Przedstawiono wybrane wyniki badań wstępnych. W pierwszym etapie na podłoże stali niestopowej (wag. 98,5\% Fe) w kształcie płytki o wymiarach $90 \times 20 \mathrm{~mm}$ i grubości $2 \mathrm{~mm}$, natryskiwana była metodą łukową warstwa aluminium o grubości ok. 0,2 mm. Na rysunku 1 przedstawiono mikrostrukturę warstwy aluminium po natryskiwaniu.

Natryskiwanie wykonano technologią łukową przy zastosowaniu następujących parametrów: natężenie prądu $150 \mathrm{~A}$, napięcie łuku $30 \mathrm{~V}$, ciśnienie powietrza 0,5 MPa, odległość dyszy pistoletu od przedmiotu $300 \mathrm{~mm}$. W procesie wykorzystano drut aluminiowy

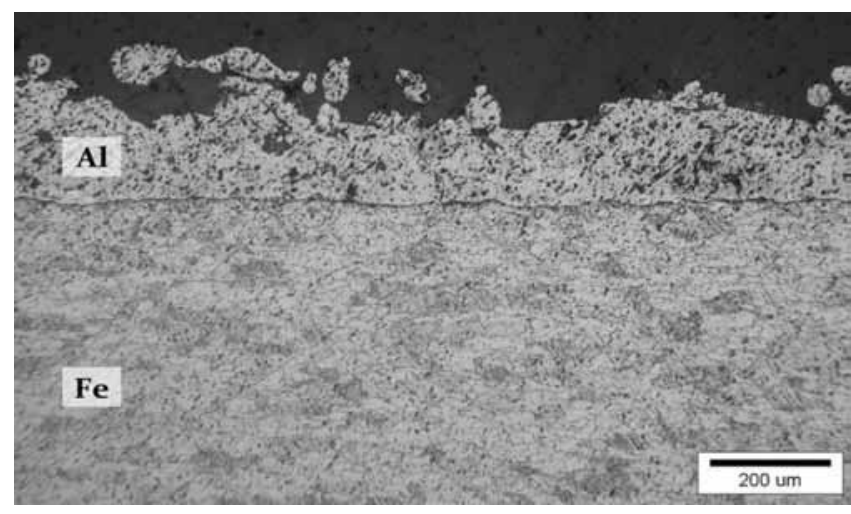

Rys. 1. Mikrostruktura natryskanej termicznie warstwy aluminium na podłożu ze stali S235JR, 100x

Fig. 1. The microstructure of thermally sprayed aluminum layer onto the S235JR steel, 100x

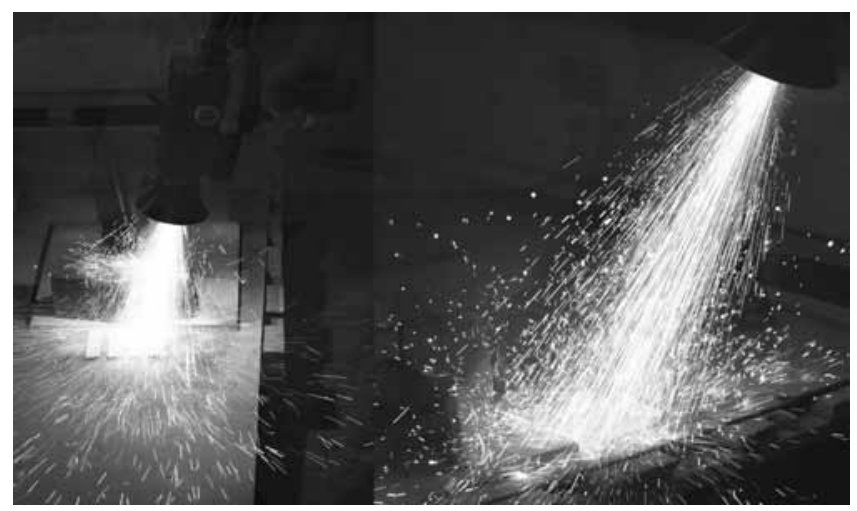

Rys. 2. Proces natryskiwania łukowego aluminium na podłoże stalowe Fig. 2. Arc spraying of aluminum onto the steel substrate

o grubości 1,6 mm. Podczas natryskiwania temperatura podłoża nie przekroczyła $100^{\circ} \mathrm{C}$. Na rysunku 2 przedstawiono proces natryskiwania łukowego warstwy aluminium na podłoże stalowe. W tym etapie dwa podstawowe składniki Al (powłoka) i Fe ze stalowego podłoża przygotowane zostały do stopienia i syntezy.

W kolejnym etapie nałożona powłoka $z$ aluminium była przetapiana wraz z warstwą stalowego podłoża (na całkowitej głębokości ok. 0,4 mm) skoncentrowaną wiązką plazmy (mikroplazmy). Do przetapiania zastosowano urządzenie FRONIUS PlasmaModule 10. Powłokę z podłożem przetapiano impulsowo przy następujących parametrach: maksymalne natężenie prądu $25 \mathrm{~A}$, napięcie łuku $11,7 \mathrm{~V}$, osłona gazowa - argon podawany z natężeniem przepływu 12 l/min, gaz plazmowy - argon (natężenie przepływu 0,6 l/min), odległość dyszy od przetapianej warstwy $-3 \mathrm{~mm}$, prędkość przesuwu palnika - $15 \mathrm{~mm} / \mathrm{min}$. Podczas przetapiania temperatura podłoża nie przekraczała $250^{\circ} \mathrm{C}$.

Kąpiel metaliczna (obszar ciekłego metalu) składała się w równym stopniu $z$ materiału powłoki aluminiowej oraz częściowo przetopionego podłoża stalowego. Proces ten przedstawiono schematycznie na rysunku 3. 


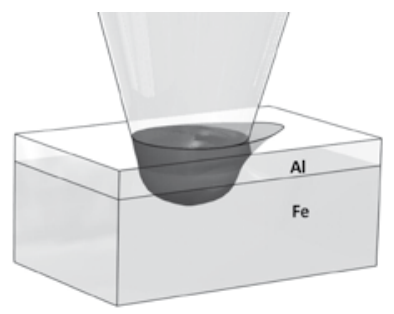

Rys. 3. Schemat procesu przetapiania mikroplazmowego komponentów

Fig. 3. The scheme of microplasma remelting of $\mathrm{Al}$ and $\mathrm{Fe}$ components

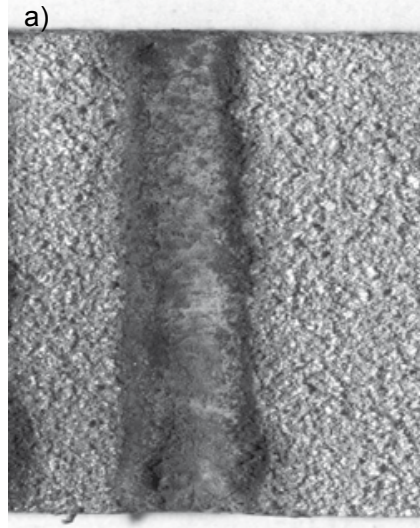

b)

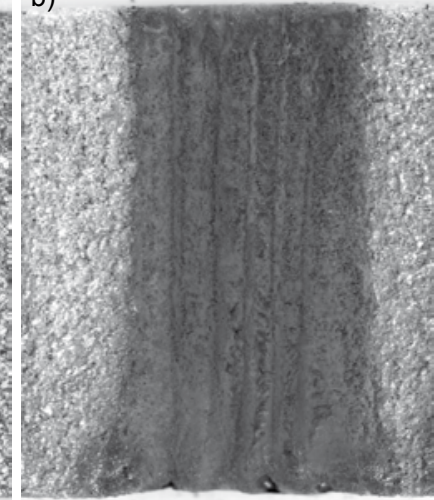

Rys. 4. Widok zewnętrznej powierzchni próbki po przetapianiu: a) ścieg pojedynczy, b) przetapianie wielościegowe

Fig. 4. The surface view of a sample after remelting: a) single pass, b) multiple lap passes

Na rysunku 4 przedstawiono widok zewnętrznej powierzchni próbki po przetapianiu. Szerokość ściegu wynosiła ok. $3 \mathrm{~mm}$. Uzyskanie dużej powierzchni tak wytworzonego stopu wymaga wykonania wielu ściegów zachodzących wzajemnie na siebie na szerokość ok. $1 \mathrm{~mm}$. Na rysunku 4a przedstawiono powierzchnię pojedynczego ściegu, natomiast na rysunku 4b pokazano powierzchnię $z$ wieloma zachodzącymi na siebie ściegami.

W przedstawiony sposób stworzono warunki metalurgiczne do powstania stopu składającego się $\mathrm{z}$ atomów aluminium i żelaza w proporcjach ok. 50/50. Wykonano podstawowe badania metalograficzne w celu scharakteryzowania mikrostruktury oraz średniej twardości warstw. Na rysunku 5 pokazano budowę mikrostrukturalną przed przetopieniem (rys. 5a) i po przetopieniu (rys. 5b) warstwy natryskanego aluminium. W obszarze nowo powstałego stopu obserwujemy charakterystyczną dla faz międzymetalicznych komórkową budowę mikrostrukturalną o średnim rozmiarze ziarn na poziomie $20 \mu \mathrm{m}$ oraz dyspersyjne wydzielenia $\mathrm{Fe}_{2} \mathrm{O}_{3} \mathrm{O}$ wymiarach nieprzekraczających $2 \mu \mathrm{m}$. Obecność cząstek $\mathrm{Fe}_{2} \mathrm{O}_{3}$ równomiernie rozproszonych w objętości obszaru przetopienia może mieć pozytywny wpływ m.in. na właściwości trybologiczne wytworzonej warstwy. Analizowana warstwa jest wolna od pęknięć i porowatości charakteryzujących warstwy natryskiwane. Zapewnia to wysoki poziom szczelności i brak karbów o charakterze geometrycznym, koncentrujących naprężenia. Największą zaletą w stosunku do powłok natryskiwanych jest metalurgiczne związanie $z$ podłożem zapewniające przyczepność warstwy na poziomie o rzad wielkości wyższym niż dla powłok natryskiwanych. Na rysunku 6 pokazano dyfraktogram powstałej warstwy. Wyniki rentgenowskiej analizy fazowej potwierdzają obecność fazy Fe-Al wtórnego roztworu stałego jako głównego składnika strukturalnego, a jednocześnie potwierdzają nieznaczny udział innych faz ubocznych jak $\mathrm{Fe}_{2} \mathrm{O}_{3}$ oraz $\mathrm{Fe}_{2} \mathrm{Al}_{5}$. Faza $\mathrm{Fe}_{2} \mathrm{O}_{3}$ powstała podczas przetapiania warstwy natryskanej z podłożem na skutek reakcji żelaza z tlenem atmosferycznym. We wcześniejszym etapie, tj. po natryskiwaniu, nie zarejestrowano jej obecności w warstwie.

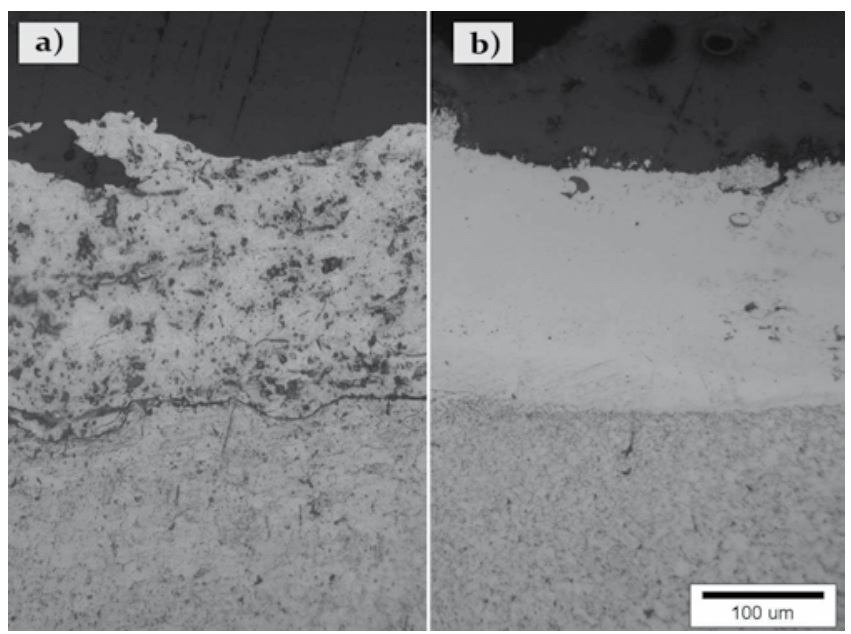

Rys. 5. Mikrostruktura warstwy powierzchniowej a) przed przetopieniem, b) po przetopieniu, 200x

Fig. 5. Microstructure of surface layer: a) before remelting, b) after remelting, 200x

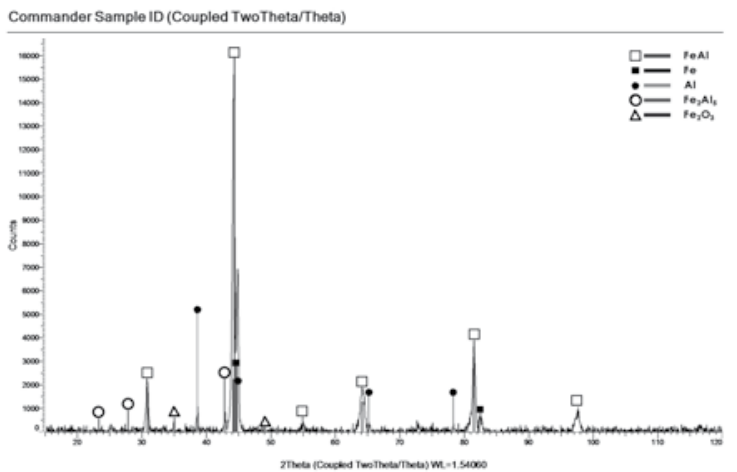

Rys. 6. Dyfraktogram przetopionej powłoki

Fig. 6. Diffraction patterns of remelted aluminum layer

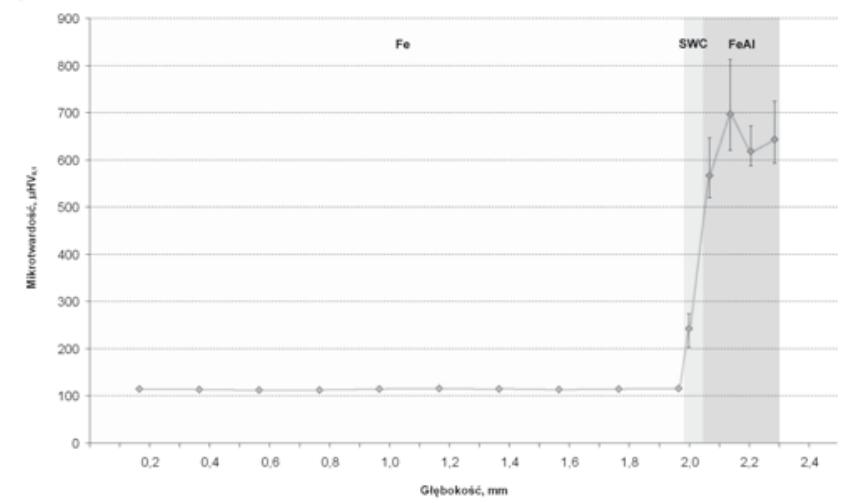

Rys. 7. Rozkład twardości w stalowym podłożu i wytworzonej powłoce

Fig. 7. Microhardness distribution across the steel substrate and produced FeAl layer 
Rozkład twardości w stalowym podłożu oraz wytworzonej warstwie przedstawiono na rysunku 7 . Badanie wykonano na mikrotwardościomierzu LeitzWetzlar. Twardość próbki po stronie podłoża badano do głębokości ok. 2,3 mm celem ujawnienia ewentualnego oddziaływania cyklu cieplnego również na podłoże. W podłożu odnotowano wzrost twardości do poziomu ok. $400 \mu \mathrm{HV} 0,1$ jedynie $w$ obszarze strefy wpływu ciepła (SWC), która obejmowała pasmo o szerokości ok. 0,05 $\mathrm{mm}$, bezpośrednio przyległe do granicy wtopienia. W warstwie właściwej zarejestrowano twardość w zakresie wartości $530 \div 810 \mu \mathrm{HV} 0,1$. Jest to poziom właściwy dla wtórnego roztworu stałego FeAl. Otrzymane wyniki odzwierciedlają jednorodność chemiczną, strukturalną i fazową wytworzonej warstwy.

\title{
Podsumowanie
}

Zaproponowana metoda jest alternatywa dla stosowanych metod modyfikacji powierzchni stalowych, opartych na pokrywaniu ich drogimi gotowymi fazami międzymetalicznymi (najczęściej w formie proszku). Największą zaletą opracowanej metody jest mały koszt stosowanych materiałów Al i stali (Fe) oraz wytwarzanie z nich nowego stopu na powierzchni modyfikowanego elementu podczas przetapiania powłoki i podłoża. Oprócz stosunkowo niskiego kosztu uzyskania stopu na bazie uporządkowanej fazy międzymetalicznej FeAl, taki sposób wytwarzania pozwala na uzyskanie wysokiego poziomu przyczepności powłoki do podłoża, o rząd wielkości wyższego niż powłok natryskiwanych termicznie, a właściwego dla metod napawania. Ponadto, zastosowane źródło ciepła przy przetapianiu w postaci skoncentrowanej wiązki mikroplazmowej umożliwia selektywne prowadzenie procesu przetapiania na wyizolowanym obszarze części maszyn.

Przedstawiona metoda daje możliwość wytwarzania in-situ warstw ochronnych bazujących na roztworze wtórnym FeAl, które swoją budową, właściwościami mechanicznymi i użytkowymi mogą wytyczać nowe kierunki zastosowań na elementy maszyn poddane wysokim obciążeniom mechanicznym oraz cieplnym i podlegające silnemu zużyciu ściernemu.

\section{Literatura}

[1] Wiliama J.C.: Intermetallics for structural applications: potential, reality and road ahead, Structural Intermetallics, ed. M.V. Nathal at al., TMS 1997, 3-8.

[2] Bystrzycki J., Varin R.A., Bojar Z.: Postępy w badaniach stopów na bazie uporządkowanych faz międzymetalicznych $z$ udziałem aluminium, Inżynieria Materiałowa 1996, 5, s. 137-149.

[3] Durejko T., Bojar Z.: Materiały na bazie faz międzymetalicznych $z$ układu Fe-Al otrzymywane zmodyfikowaną metodą prasowania w podwyższonej temperaturze. Composites No. 2/2005.
[4] Senderowski C., Bojar Z.: Intermetaliczne powłoki ochronne otrzymywane przez gazodetonacyjne natryskiwanie samorozpadowych proszków Fe-Al, Inżynieria Materiałowa 2004, 5, s. 880-884.

[5] Chmielewski T., Golański D.: The new method of in-situ fabrication of protective coatings based on FeAl intermetallic compounds. Proceedings of the Institution of Mechanical Engineers, Part B, Journal of Engineering Manufacture, 2011, Vol. 225 (4), s. 611-616.

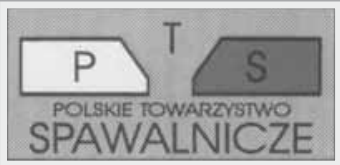

\section{POLSKIE TOWARZYSTWO SPAWALNICZE Oddział w Opolu}

\author{
informuje o organizacji
}

\section{KONFERENCJI SPAWALNICZEJ „SPAWANIE W ENERGETYCE”}

w dniach od 24 do 26 kwietnia 2012 r. w Ośrodku Ziemowit w Jarnoltówku

- sesje referatowe

- wystawy techniczne

- imprezy towarzyszące

Wszystkich zainteresowanych udziałem w konferencji zapraszamy do skontaktowania się z Polskim

Towarzystwem Spawalniczym - Oddział w Opolu.

Dodatkowe informacje:

Pocica Anna, tel. 487740062 51, e-mail: a.pocica@po.opole.pl Derwich Tomasz, tel. 487740192 95, e-mail: tomasz.derwich@esab.pl

Korespondencję prosimy kierować pod adresem: POLSKIE TOWARZYSTWO SPAWALNICZE - ODDZIAŁ W OPOLU ul. A. Struga 10, 45-073 OPOLE (fax: 487740192 01) 